Behavior and Social Issues, 21, 165-187 (2012). (C) Jeffrey N. Weatherly, Richard A. Wise, \& Adam Derenne. Readers of this article may copy it without the copyright owner's permission, if the author and publisher are acknowledged in the copy and the copy is used for educational, not-for-profit purposes. doi: 10.5210/bsi.v.2110.4183

\title{
Probability Discounting of Legal and Non-Legal OUTCOMES
}

\author{
Jeffrey N. Weatherly ${ }^{1}$ \\ Richard A. Wise \\ Adam Derenne \\ University of North Dakota
}

\begin{abstract}
Probability discounting describes how the subjective value of an outcome changes because its delivery is uncertain. Although many legal decisions involve probability discounting, it has not been systematically studied. Participants were recruited to complete a probability-discounting task that assessed two legal (i.e., murder \& embezzlement) and two non-legal (winning a sweepstakes \& receiving medical treatment) hypothetical scenarios. They also completed several measures to assess attitudes related to legal issues. Different rates of discounting were observed across the four scenarios. Factor analysis indicated that discounting of the legal scenarios loaded onto a different factor than one of the non-legal scenarios (with the other cross loading on both). Only the participants' estimation of what constituted reasonable doubt was a reliable predictor of their rates of discounting of the legal outcomes. The present results have a number of potential social implications, both for the study of probability discounting and the understanding of legal decision-making. They also highlight the need for more experimental research on overt behavior.
\end{abstract}

KEYWORDS: probability discounting, legal decision-making, law

Discounting describes when the subjective value of an outcome is altered because that outcome is either uncertain or delayed (see Madden \& Bickel, 2010). When the potential outcome is a gain, as opposed to a loss, the general finding is that the subjective value of the outcome decreases as it becomes increasingly improbable or delayed. For instance, if someone owed you $\$ 100$, but there was only a $50 \%$ chance that the person was going to be able to pay you back, you may be willing to accept $\$ 50$ rather than taking the chance of not getting any of the

${ }^{1}$ Correspondence concerning this article should be addressed to Jeffrey N. Weatherly, Ph.D., Department of Psychology, University of North Dakota, Grand Forks, N.D. 58201. Email: jeffrey.weatherly@und.edu 
money. Likewise, if there was only a $25 \%$ chance the person was going to pay, then you may be willing to accept \$25 instead of taking the risk of getting nothing.

How steeply the subjective value decreases as the full outcome becomes increasingly improbable or delayed determines that individual's "rate" of discounting. Within a behavior-analytic framework, rates of probability discounting can be interpreted as a metric of risk taking. Steep rates of discounting represent decision-making behavior that is risk averse. Shallow rates of discounting or no discounting represent decision-making behavior that is risk seeking.

Psychologists within and outside of behavior analysis have been interested in rates of discounting for a variety of reasons. First, how people discount (hypothetical) outcomes has been correlated with certain psychological disorders, such as substance abuse (e.g., Yi, Mitchell, \& Bickel, 2010), pathological gambling (e.g., Petry \& Madden, 2010), and attention deficit/hyperactivity disorder (e.g., Williams, 2010). Second, the process of discounting appears to broadly affect choice behavior. For instance, the process of discounting can be applied to economic (e.g., Pearce, Groom, Hepburn, \& Koundouri, 2003), environmental (e.g., Hardisty \& Weber, 2009), and social (e.g., Weatherly, Plumm, \& Derenne, 2011) issues. Discounting also plays a role in public policy decisions. For example, policy makers must often determine whether to work at length on a comprehensive policy or to craft piecemeal legislation that can pass immediately. Which of those choices is the "correct" one may depend on how citizens (and/or the policy makers) discount the specific outcome addressed by the policy.

One area that, to our knowledge, has yet to be systematically examined in the context of discounting is legal decision making. Lack of research in this area is surprising because of the importance of law to society and because discounting plays such a prominent role in the law. It has been estimated that between 90 and 95\% of all criminal cases are resolved by plea bargains (Sweeney \& Haney, 1992). Further, an even greater percentage of civil cases are settled without a trial than are criminal cases (Greene \& Heilbrun, 2011). Both plea bargains and settlements represent a form of discounting. For example, most criminal defendants must choose between accepting a plea bargain, which offers a smaller but certain penalty, or going to trial and facing a substantially greater penalty if convicted. Likewise, the prosecutor must determine whether it is better to offer a defendant a plea bargain and ensure that the defendant receives some penalty or go to trial seeking a greater penalty, but also risking a not-guilty verdict. If a 
prosecutor does decide to offer a plea, he or she must also decide what type of plea bargain to offer.

Moreover, some states require prosecutors to consult with the families of victims before offering a plea bargain, and in all states a judge must approve a plea bargain for it to be valid (Greene \& Heilbrun, 2011). All of these scenarios require the participants to engage in probability discounting. Finally, how members of the general public view the justice system is shaped in part by their judgments of the fairness of plea bargains and settlements. Phrased differently, people's view of the legal system will likely be related to how they would discount outcomes in such situations.

Another reason to be interested in discounting in legal situations is because research has suggested that rates of discounting may vary as a function of the type of outcome being discounted. For instance, Hardisty and Weber (2009) found that participants discounted health-related outcomes differently than monetary or environmental outcomes. Odum and Rainaud (2003) reported differences in discounting when the outcomes involved consumable versus non-consumable commodities. Weatherly, Terrell, and Derenne (2010) had participants discount five different outcomes. Using factor analysis, they demonstrated a two-factor solution. That is, rates of discounting for a particular outcome (e.g., money) were predictive of discounting of other outcomes (e.g., cigarettes), as long as those outcomes were within the same domain of outcomes. Rates of discounting were not predictive of discounting of outcomes in another domain (e.g., receiving medical treatment), a result that was subsequently replicated by Weatherly and Terrell (2011). In short, how individuals discount other types of outcomes (e.g., money) may not predict how they discount legal outcomes.

The present study was designed as a preliminary investigation of how individuals discount outcomes in a hypothetical legal context. This investigation was undertaken for several reasons. One reason was because many researchers have argued that rates of discounting are general (e.g., see Yi et al., 2010) and can potentially be viewed as a trait variable (see Odum, 2011). However, there is growing evidence that people do not discount all outcomes in a like manner (e.g., Odum \& Rainaud, 2003; Weatherly \& Terrell, 2011; Weatherly et al., 2010) and determining if people discount legal and non-legal outcomes differently would help clarify this debate. Likewise, discounting of different crimes may also depend on the nature of the crime. For example, violent and non-violent crimes may be discounted differently. Determining whether this possibility is true may be important for both theoretical and practical reasons.

Ideally, studying overt behavior would be preferable to studying decisions about hypothetical situations because individuals may not behave the way they 
say they will. However, obtaining data from individuals making actual legal decisions would be difficult (e.g., prosecutors would likely be unwilling to divulge information about particular plea bargains they may be considering) and one would lose the ability to control potentially important factors across cases (e.g., the crime, the alleged perpetrator and/or victim). Given that no previous research exists on the present topic of study, and that research on discounting suggests that results from studies using hypothetical outcomes can produce valid results that are applicable in "real life" (e.g., Locey, Jones, \& Rachlin, 2011), we investigated hypothetical scenarios.

Beyond discounting, very little systematic research has been conducted on what factors influence plea bargaining despite the importance of plea bargaining to the criminal justice system (Kramer, Wolbransky, \& Heilbrun, 2007; McAllister, 2008). The few studies that have been conducted on plea bargaining have generally used decision theory to predict pleas (Kramer et al., 2007; McAllister, 2008). According to decision theory, when deciding what plea to offer or whether to accept a plea, both sides consider two factors: The probability the defendant will be convicted of the crime, and the sentence that the defendant would receive if convicted. According to this theory, the fairness of a plea can be assessed by multiplying these two factors together. For instance, if the probability that a defendant will be convicted is $50 \%$ and if the potential sentence for the defendant if convicted is 10 years, decision theory would predict that the fair plea value of the case would be five years (McAllister \& Bregman, 1986).

Research on decision theory supports the idea that both prosecutors and attorneys consider the probability of conviction and the potential sentence when they evaluate plea bargains in criminal cases. For example, McAllister and Bregman (1986) determined how the strength of a case and the potential sentence impacted plea bargaining of prosecutors and defense attorneys. Six hypothetical scenarios involving various white-collar crimes were mailed to two prosecutors and two defense attorneys in each of 47 states. In the hypotheticals, the probability of conviction was 20,50 , or $80 \%$, and the sentence if the defendant was convicted was 2 or 5 years. Prosecutors decided for each hypothetical case if they would offer a one-year plea bargain, and the defense attorneys decided if they would accept a one-year plea bargain.

Results showed that the probability of conviction and the severity of the sentence were important factors in the attorneys' plea decisions. As probability of conviction and severity of the sentence increased, prosecutors were less willing to plead, and defense attorneys were more willing to plead. The results also indicated, however, that these two factors were not sufficient by themselves to 
always predict attorneys' plea decisions, suggesting that decision theory might be incomplete.

Kramer et al. (2007) also found that the probability of conviction and the potential sentence were not the only factors that affect plea bargains. They mailed defense attorneys one of eight plea bargaining vignettes that varied the strength of the case, the potential sentence, and the defendant's desire to plea bargain. Like McAllister and Bregman (1986), results showed that the strength of evidence was an important factor in defense attorneys' decisions to recommend a plea. The defense attorneys were generally more likely to recommend a plea when the evidence against the defendant was strong rather than when it was weak.

Kramer et al. (2007) also showed that potential sentence was an important factor in the attorney's plea recommendation in two circumstances when the defendant wished to go to trial. One was when the evidence was strong and the potential sentence was long. The second was when the evidence was weak and the defendant was facing a shorter sentence. In all other circumstances, however, the effect of the potential sentence on plea recommendations was less clear and appeared to depend on other factors. The defendant's wishes also impacted plea decisions though surprisingly in most instances the defense attorneys' plea recommendations were contrary to the defendant's wishes. Kramer et al. (2007) concluded "that defense attorney plea decision-making involves more than just considering the potential sentence and the probability of conviction" (p. 582). Legal scholars such as Hollander-Blumhoff (1977) and Bibas (2004) have also hypothesized that factors other than the strength of the case and the potential sentence influence plea bargains. Studying probability discounting in hypothetical legal situations may be a good first step in identifying those factors.

While certainly outside the framework of behavior analysis, legal researchers have long maintained that subject factors such as attitudes and beliefs impact legal decision making (Devine, Clayton, \& Dunford, 2001; Martin \& Cohn, 2004). One example is jurors' decisions. For instance, Lecci and Myers (2008) developed a questionnaire that purportedly assesses six different attitudinal constructs related to extralegal decision making that predicts jurors' verdicts. If such subject factors predict legal decision making, then they may also predict how individuals discount legal outcomes. Likewise, if these putative attitude measures do not predict decision making in hypothetical situations, then it is less likely they would predict overt behavior when people make similar "real life" decisions.

Participants in the present study completed a probability-discounting task. This task assessed two hypothetical legal (i.e., plea bargains for guilty defendants charged with either murder or embezzlement) and two hypothetical non-legal (i.e., winning $\$ 100,000$ in a sweepstakes and receiving medical treatment) 
outcomes. For the legal outcomes, the participants were asked to recommend a plea bargain for five different probabilities of conviction $(1,10,50,90, \& 99 \%)$ after being informed of the potential sentence or fine if the defendant was convicted of the crime. Participants also completed self-report measures of their attitudes regarding legal decision making.

Our hypotheses were as follows. First, given that research suggests that rates of discounting may vary as a function of type of outcome, we predicted that different rates of probability discounting would be observed across the different outcomes. In terms of the legal outcomes we predicted that participants would discount outcome in the murder scenario more than the outcome in the embezzlement scenarios. We made this prediction based on the magnitude effect (Thaler, 1981). With probability discounting, the magnitude effect is observed when participants display more discounting (i.e., they become more risk averse) as the magnitude of the outcome is increased (e.g., see Estle, Green, Myerson, \& Holt, 2006). Our hypothesis was based on the assumption that because murder is subject to more severe punishment than embezzlement, it would have a greater magnitude than embezzlement.

Second, because research has suggested that decision theory does not encompass all factors that influence plea bargains, we predicted that observed rates of discounting would differ significantly from those predicted by decision theory (which, in the present study, would equate to half of the maximum sentence or fine). However, we did not make a specific prediction as to the direction of that difference. Phrased differently, we did not have an a priori prediction of whether participants would be more risk averse (i.e., steep rates of probability discounting) or risk seeking (i.e., shallow rates of probability discounting) than predicted by decision theory.

Third, because past factor analyses have shown that differently discounted outcomes can fall into different domains, we predicted that a factor analysis of the present data would produce multiple domains, with one consisting of legal outcomes that would be distinct from discounting of the non-legal outcomes. Finally, because research suggests that peoples' self-reported extralegal attitudes predict their verdicts, we hypothesized that these self-reported attitudes would also predict how they discounted the hypothetical legal outcomes. We did not, however, have a priori predictions as to which specific self-reported attitude measures would predict discounting. Lastly, we predicted that participants' selfreported extralegal attitudes would not predict how they discounted hypothetical non-legal outcomes. 


\section{Method}

\section{Participants}

The participants were 155 (129 female; 26 male) students enrolled in a psychology course at the University of North Dakota. The mean age of the participants was 19.8 years $(\mathrm{SD}=3.5$ years) and their self-reported grade point average was 2.7 out of $4.0(\mathrm{SD}=1.5)$. The vast majority $(149 ; 96.1 \%)$ of the participants self-reported as Caucasian. Participants received (extra) course credit in return for their participation.

\section{Materials and Procedure}

Participants completed the materials using an online data-management system (SONA Systems, Ltd; Version 2.72; Tallinn, Estonia). This system was able to track participation at an individual level, thus ensuring that participants enrolled in multiple psychology courses could complete the study only one time. Prior to completing any materials, the system presented each participant with a description of the study as approved by the Institutional Review Board at the University of North Dakota. Continuation beyond this presentation constituted the granting of informed consent.

The first form the participants completed was a short demographic questionnaire. This form asked participants about the information reported in the participants' section. It also contained two questions related to their opinions regarding legal issues. The first was "In your opinion, 'reasonable doubt' means that there is at least a _ \% chance that the person committed the crime." The participant then generated a percentage. We included this question because research indicates that there is wide variability in how people quantify reasonable doubt, and it is a good predictor of jurors' verdicts (Dhami, 2008). The second question was "What is your opinion of the death penalty?" To answer this question, participants chose between "Favor it" and "Oppose it." Opinions on the death penalty also predict juror verdicts and researchers have argued that favoring the death penalty is associated with a strong belief in a just world, authoritarian beliefs, and an internal locus of control (Devine et al., 2001; Butler \& Moran, 2007).

The second form participants completed was the Pretrial Juror Attitudes Questionnaire (PJAQ; Lecci \& Myers, 2008). The PJAQ is a 29-item questionnaire that purports to measure potential jurors' attitudinal biases. Respondents answered each question on a 5-point Likert-like scale that ranges 
from 1 (strongly disagree) to 5 (strongly agree). The PJAQ contains six subscales: system confidence $(\mathrm{CON})$, conviction proneness $(\mathrm{CP})$, cynicism towards the defense $(\mathrm{CYN})$, racial bias $(\mathrm{RB})$, social justice $(\mathrm{SJ})$, and innate criminality (INNCR). Lecci and Myers (2008) reported that the predictive validity of the PJAQ is superior to that of other measures designed to assess jurors' attitudinal biases.

Lastly, participants completed a probability-discounting task, which tested four different outcomes. The outcomes were hypothetical scenarios that involved a potential plea bargain in a murder case, a potential plea bargain for a $\$ 100,000$ fine for a defendant who committed embezzlement, winning a $\$ 100,000$ sweepstakes, and receiving medical treatment for a serious medical condition. The participants were informed that the defendant committed the crime in both legal scenarios. The exact phrasing of each scenario can be found in the Appendix.

These particular outcomes were chosen for several specific reasons. The crimes of murder and embezzlement were chosen because they arguably differed both in their moral and practical severity. The outcome of winning a hypothetical amount of money was chosen because it is the most widely studied outcome in the discounting literature (see Madden \& Bickel, 2010). The amount of money, $\$ 100,000$, was chosen because it equaled the amount of money in the embezzlement scenario. The outcome of hypothetically receiving medical treatment for a serious condition was chosen because previous research (Weatherly et al., 2010; Weatherly \& Terrell, 2011) has suggested that this outcome is in a different domain for delay discounting than obtaining a hypothetical amount of money. Thus, if that result was replicated, we could determine whether discounting of the two hypothetical crime outcomes was associated with discounting of the hypothetical outcomes of money, medical treatment, both, or neither.

Participants completed five questions pertaining to each outcome, with the questions differing in terms of the probability of the outcome. The same five probabilities (i.e., 1, 10, 50, 90, or 99\%) were used for each outcome. The method of data collection was the fill-in-the-blank method (Chapman, 1996). Participants answered each discounting question by generating their response. This method produces reliable data (Weatherly, Derenne, \& Terrell, 2011) that are sensitive to differences in the type of outcome tested (Weatherly et al., 2010; Weatherly \& Terrell, 2011). Participants were asked all five questions about a particular hypothetical outcome before questions about another outcome were presented. The order that the hypothetical outcomes were presented varied randomly across participants, as did the order of the five probabilities for each hypothetical outcome. 


\section{Data Analysis}

With probability discounting, the respondent's rate of discounting is typically determined by plotting the respondent's responses in terms of "odds against" the outcome occurring $(\Theta=(1-p) / p)$. Once plotted, there are several different ways to determine the rate of discounting, including fitting the data with a hyperbolic function (Mazur, 1987), with a hyperboloid function (Green, Myerson, \& Ostaszewski, 1999), and/or determining the area under the discounting curve (AUC; Myerson, Green, \& Warusawitharana, 2001). Using AUC is sometimes favored because it does not assume the mathematical form that the data will take and because it typically produces parametric data that do not need transformation before statistical analyses can be conducted.

We relied on a variation of AUC and did so for two reasons. The first was to ensure that certain responses would not have a disproportionate influence on the overall calculation. That is, most of the area under the curve was comprised by the distance between $\Theta=9.00$ and $\Theta=99.00$ (i.e., when the probability of the outcome was $10 \%$ and $1 \%$, respectively), and the usual method of calculating AUC would reduce in importance participants' responses to the other probabilities. The second reason was that decision theory assumes that all probabilities are treated equally.

We addressed these issues by using simple averaging to give all responses equal weight. As this method deviates from the traditional method of calculating AUC, we refer to these results below as proportions of the full possible amount rather than AUC. With this method, as well as with AUC, values are inversely related to discounting, with low values indicating high levels of discounting and high values indicating little or no discounting. Expressed differently, high levels of discounting indicate risk aversion and low levels of discounting suggest indicate risk proneness. Importantly, because decision theory assumes that the decision will be the product of the probability of conviction and the maximum outcome, decision theory would predict that the observed proportions, for both the murder and embezzlement scenarios, would be 0.50 . Nonetheless, the conclusions drawn from the analyses that follow would not have differed had we used the traditional method of calculating AUC (i.e., Myerson et al., 2001).

Factor analysis was also used to determine how participants discounted the different outcomes. Factor analysis potentially divides outcomes into different domains; outcomes within a given domain are mutually predictive. Previous research has shown that different domains of discounted outcomes can exist, with, for example, money and cigarettes falling into one domain, and medical treatment into another (e.g., Weatherly et al., 2010). 
WEATHERLY, WISE, \& DERENNE

\section{Results}

\section{Differences in Discounting}

Rates of discounting were analyzed by subjecting the discounting proportions for each outcome for all participants to a one-way (Type of Outcome) repeated-measures analysis of variance. This analysis yielded a significant main effect of type of outcome, $F(3,462)=79.49, p<.001$, partial Eta squared $=.340$, indicating that different rates of discounting were observed across the four outcomes. Tukey HSD post hoc comparisons indicated that the rates of discounting of the murder (mean $=0.44, \mathrm{SD}=0.21)$, embezzlement (mean $=0.53$, $S D=0.16)$, sweepstakes (mean $=0.49, \mathrm{SD}=0.14$ ), and medical treatment (mean $=0.70, S D=0.16$ ) outcomes all differed significantly from one another. For these analyses, statistical significance was met a $p \leq .05$.

Follow-up analyses were conducted on only the outcomes of murder and embezzlement to test the predictions of decision theory (i.e., whether the observed proportions differed from 0.50). To make these determinations, two one-sample $t$ tests were conducted, with the data tested against the expected outcome of 0.50 . Also, because these data had been included in the previous analyses, the threshold for statistical significance was reduced to $p \leq .025$ so as to guard against Type I errors. The results for discounting of the murder scenario indicated that the proportions were significantly below $0.50, t(154)=-3.58, p<.001$, indicating that participants' decision making about this hypothetical scenario was more risk averse than predicted by decision theory. Analysis of the embezzlement scenario indicated that he proportions were significantly above $0.50, t(154)=2.51, p=$ .013 , indicating that participants' decision making about this hypothetical scenario was more risk seeking than predicted by decision theory.

These conclusions, however, are based on averages across all of the probabilities. Decision theory may make accurate predictions at some probabilities. To test this possibility, one-sample $t$ tests were also conducted on participants' responses to each of the hypothetical crime scenarios at the extreme probabilities. For the murder scenario, participants' acceptable plea bargain was significantly more than 1 year when there was only a $1 \%$ chance of conviction, $t(154)=7.98, p<.001$, and was significantly less than 99 years when there was a $99 \%$ chance of conviction, $t(154)=-11.87, p<.001$. Similarly for the embezzlement scenario, participants' acceptable plea bargain was significantly more than $\$ 1,000$ when there was only a $1 \%$ chance of conviction, $t(154)=7.73$, $p<.001$, and was significantly less than $\$ 99,000$ when there was a $99 \%$ chance of conviction, $t(154)=-6.66, p<.001$. Thus, regardless of the crime, participants 
were more risk seeking than predicted by decision theory when the odds of conviction were very low and were more risk averse than predicted by decision theory when the chances of conviction were high, but not certain.

\section{Domains of Discounting}

To determine whether the discounting of the hypothetical legal and non-legal outcomes was within the same or different domains, a series of analyses were conducted on the discounting proportions for the four different outcomes. The first analysis was a principal components analysis (PCA) using PASW Statistics Version 17.0. The criteria used for determining the number of factors to retain were eigenvalues greater than 1.0, inspection of the scree plot, and logical item loadings (Cattell, 1966; Tabachnick \& Fidell, 2007). A multi-factor solution was identified, so the second analysis was a principal axis factoring (PAF) analysis specifying the number of factors identified in the PCA. For the PAF analysis, a Varimax rotation was employed.

The results of these analyses are presented in Table 1. The PCA indicated a two-factor solution. The PAF analysis accounted for $68.18 \%$ of the variance and the two factors were correlated at 0.20 . As can be seen in Table 1, discounting of the murder and embezzlement scenarios loaded onto Factor 1. Discounting of the sweepstakes cross loaded (nearly identically) on both Factors 1 and 2 . Discounting of medical treatment loaded onto Factor 2, albeit inversely.

\section{Predicting Rates of Discounting}

To determine whether participants' self-reports of their legal attitudes predicted their discounting of the different hypothetical outcomes, a series of simultaneous linear regressions was conducted with the discounting proportions serving as the dependent measure and participants' responses to the two legal questions on the demographic form and their scores from the subscales of the PJAQ serving as the predictor variables. Simultaneous regressions were employed because this analysis identifies the variance accounted for by each predictor variable independent of the other variables.

Before conducting the regression analyses, however, bivariate correlations were calculated across all eight of the predictor variables. These correlations were conducted because, if highly correlated (i.e., $r \geq .50$ ) predictor variables are entered into a simultaneous regression analysis, then the resulting beta weights are unstable. The correlational analysis indicated that one pair of predictor variables was highly correlated, the CON and INNCR subscales of the PJAQ $(r=.56)$. 
WEATHERLY, WISE, \& DERENNE

Table 1. Factor Loadings from the PCA and PAF analyses conducted on the discounting proportions for all outcomes

\begin{tabular}{lcccc}
\hline Item & \multicolumn{2}{c}{$\underline{\text { PCA }}$} & \multicolumn{2}{c}{ PAF } \\
& Factor 1 & Factor 2 & Factor 1 & Factor 2 \\
\hline Murder & $\mathbf{. 7 9 7}$ & .197 & $\mathbf{. 6 2 6}$ & .097 \\
Embezzlement & $\mathbf{. 8 1 0}$ & .241 & $\mathbf{. 7 9 2}$ & .018 \\
Sweepstakes & $\mathbf{6 0 9}$ & $\mathbf{- . 3 1 9}$ & $\mathbf{. 3 2 4}$ & $\mathbf{. 3 2 5}$ \\
Medical Treatment & -.173 & $\mathbf{. 9 1 4}$ & -.002 & $\mathbf{- . 4 0 3}$ \\
\hline
\end{tabular}

Note: Factor loadings $>.3$ are indicated by bold typeface.

Overall, the INNCR scores were also more correlated to the other predictor variables than were the CON scores. Therefore, the INNCR scores were omitted from the following regression analyses. Statistical significance was set at $p \leq .05$.

The regression analysis of the discounting proportions for the hypothetical murder scenario indicated that the regression model was significant, $F(7,141)=$ 2.38, $p=.025, R^{2}=.106$. In terms of individual predictor variables, both the respondents' percentage of what constituted reasonable doubt $(\beta=0.171, p=$ $.040)$ and their CP scores $(\beta=0.217, p=.028)$ were significant predictors of discounting. In both cases, high percentages of reasonable doubt and $\mathrm{CP}$ scores indicated risk proneness in terms of receiving the outcome (i.e., higher discounting proportions).

The regression analysis of the discounting proportions for the hypothetical embezzlement scenario indicated that the regression model was significant, $F(7$, $141)=2.06, p=.05, R^{2}=.093$. In terms of individual predictor variables, only one predictor was significant, and that was the respondents' percentage of what constituted reasonable doubt $(\beta=0.215, p=.010)$. Again, participants who indicated a high percentage of what constituted reasonable doubt tended to be risk prone in their discounting decisions.

The regression analysis of the discounting proportions for the hypothetical sweepstakes scenario indicated that the regression model was not significant, $F(7$, $141)<1.00, p=.904, R^{2}=.019$, nor were any of the predictor variables significant. The regression analysis of the discounting proportions for the hypothetical medical treatment scenario, on the other hand, indicated that the model was significant, $F(7,141)=2.68, p=.012, R^{2}=.117$. The only significant 
predictor of discounting of medical treatment was participants' view on the death penalty $(\beta=0.189, p=.026)$. Specifically, individuals who indicated that they opposed the death penalty tended to be risk prone when it came to obtaining medical treatment (i.e., displayed higher discounting proportions).

\section{Discussion}

We hypothesized that different rates of probability discounting would be observed across the different hypothetical outcomes. Our hypothesis was supported; rates of discounting differed for every outcome. This result also supported our hypothesis that participants would discount differently between the hypothetical murder and embezzlement scenarios. Next, we predicted that the observed proportions for the crime scenarios would differ from those predicted by decision theory (McAllister \& Bregman, 1986). That result was also observed, with lower overall proportions observed for the murder scenario and higher overall proportions observed for the embezzlement scenario than would be predicted by decision theory. Responses also differed significantly from those predicted by decision theory at the extreme probabilities. Thus, the results provide additional evidence that decision theory is insufficient to explain the factors that influence plea bargains.

Further, we hypothesized that discounting of the hypothetical legal and nonlegal outcomes would be distinct. The results showed that discounting in the murder and embezzlement scenarios was distinct from discounting in the medicaltreatment scenario. Discounting in sweepstakes scenario, however, was associated with discounting of both the legal and medical-treatment outcomes. Lastly, we hypothesized that participants' self-reports of their legal attitudes would be predictive of how they discounted the hypothetical legal, but not non-legal, outcomes. Some self-reported legal attitudes were significant predictors of discounting in the two legal scenarios, but none were significant predictors of discounting in the sweepstakes scenario. Interestingly, participants' opinion of the death penalty was predictive of how they discounted hypothetically receiving medical treatment.

\section{Implications for the Legal System}

As noted previously, little systematic research has been conducted on the process of probability discounting in legal decision making even though probability discounting is a common occurrence in the law. The results indicate that participants discount different hypothetical legal outcomes at different rates, discount hypothetical legal outcomes differently than predicted by decision 
theory, and how they discount hypothetical legal outcomes may not be predicted by how they discount certain hypothetical non-legal outcomes. This latter result suggests that researchers should not assume that, by measuring discounting of non-legal outcomes, they have determined how risk averse or risk seeking people will be in making legal decisions.

We hypothesized that certain aspects of participants' self-reported attitudes would be predictive of their discounting of the legal outcomes. When those attitudes were measured with an established instrument (i.e., the PJAQ; Lecci \& Myers, 2008), that hypothesis was rarely supported. Of the five PJAQ subscales entered into the regression analyses for discounting of the legal outcomes ${ }^{2}$, only one subscale was a significant predictor of discounting, and that occurred only for discounting in the hypothetical murder scenario. In some cases, this inability to predict discounting should not be surprising. For instance, one subscale purports to measure racial bias. However, the hypothetical legal outcomes tested in the present study were phrased so as to be ambiguous as to the race of the defendant.

Rather surprisingly, the only PJAQ subscale to significantly predict discounting was $\mathrm{CP}$, which purportedly measures attitudes about how rigorously criminals should be sought and prosecuted. Finding that this measure was related to discounting might seem intuitive, especially given that for the murder scenario participants who scored high on this measure were risk prone (i.e., willing to take the risk to get the maximum penalty). The major question is why this subscale was the only one that was predictive of discounting in the legal scenarios, and why none of the other subscales (e.g., CON, CYN, SJ), which one would have suspected would be related to discounting of these legal outcomes, were ever significant predictors? From a behavioral perspective, it may not be particularly surprising that self-reports of dispositional factors do not predict decision making and that situational factors such as the crime and the probability of conviction appear to largely control this type of behavior. In fact, from a behavioral perspective, finding that purported attitude measures poorly predict decision making in hypothetical situations provides little confidence that they would predict behavior in actual cases. With that said, the present results indicate that additional research is warranted to determine exactly what factors might predict discounting in legal situations.

Importantly, participants' response to the question about how they would quantify reasonable doubt was a significant predictor of discounting in both the murder and embezzlement scenarios. The higher the percentage of certainty that a

\footnotetext{
${ }^{2}$ Two of the subscales were highly correlated, so one of the six subscales was omitted from the analyses.
} 
participant required for no reasonable doubt, the more risk prone was the decision making in these hypothetical situations. This result needs to be replicated before it can be considered reliable. Furthermore, the phrasing of the question about reasonable doubt in the present study may have been confusing and different results may have occurred had the question been phrased differently. Nonetheless, despite these caveats, the participants' responses to the question about reasonable doubt were significant predictors of discounting and suggest that it produced systematic differences in responding.

If the present results are reliable, then two conclusions can be drawn. First, peoples' opinions about what constitutes reasonable doubt may predict their views of plea bargains, at least in hypothetical situations Additional research would be needed to determine whether they might also predict actual decision making. Second, researchers interested in legal decision making, whether hypothetical or actual, would be well advised to assess participants' opinions about what constitutes reasonable doubt.

As stated previously, the vast majority of criminal and civil cases in the U.S. are resolved by plea bargains and settlements rather than by trials. Consequently, how well the U.S. legal system functions is largely determined by the fairness of its plea bargains and settlements. The fairness of plea bargains is especially critical. Not only are the stakes generally higher in criminal than civil cases, but a variety of factors make it more difficult to take risks in criminal than in civil cases (Bibas, 2004). Because participants displayed more risk aversion in the hypothetical murder scenario than in the hypothetical embezzlement scenario suggests that the decision making of the present participants was sensitive to such complexities.

The ability of attorneys, judges, plaintiffs, and defendants to accurately discount cases is essential to fair plea bargains and settlements. There are, however, many obstacles to participants accurately discounting cases. Some of them are structural, such as attorney and judicial competency, case loads, experience, etc. Others qualify as subject variables, such as biases and the use of inappropriate heuristics in discounting cases (Bibas, 2004; i.e., behavior has come under the control of an inappropriate stimuli). These obstacles result in some defendants pleading who should go to trial, and some defendants going to trial who should plead. Consequently, scarce legal resources are often squandered on cases that should not have been tried. Even more importantly, many of the plea bargains that are struck are inequitable with defendants receiving either too lenient or too harsh sentences. These inequities in plea bargain may be more likely to occur with lower IQ, young, male, first time defendants (Bibas, 2003). 
Psychologists who study the law need to devote more time and effort to determining how the quality of plea bargains and settlements can be improved (Edkins, 2011). Discounting can play an important role in achieving this critical goal. Not only can studies on discounting be used to identify factors that impair individuals' ability to accurately discount cases, but by applying the principles of discounting to the assessment of plea bargains and settlements, attorneys, and judges may be able to more objectively evaluate them. Such a result would not only significantly enhance the efficacious use of scarce trial resources, but would also potentially produce fairer plea bargains and settlements.

\section{Implications for Discounting}

As noted previously, there has been a debate in the literature about whether rates of discounting are a general characteristic of the individual or vary systematically as a function of type and/or domain of the outcome. The present results clearly favor the latter interpretation. Absolute rates of discounting of all four hypothetical outcomes tested differed significantly from each other, indicating that discounting varied as a function of outcome. When discounting rates were factor analyzed, results showed a multi-factor solution, suggesting that different domains of outcomes were present across the four hypothetical outcomes tested.

Unlike research with delay discounting (Weatherly et al., 2010; Weatherly \& Terrell, 2011), the present results suggested that discounting of the probabilistic hypothetical monetary outcome cross loaded in the domains that contained the hypothetical legal outcomes and the hypothetical outcome of receiving medical treatment. In previous research, discounting of money was distinct from discounting of medical treatment. Exactly why this separation was not observed presently is not known. Researchers have argued that the processes of delay and probability discounting are at least partially independent (e.g., Green \& Myerson, 2004). Finding that discounting of these outcomes are independent for delay discounting, but not for probability discounting, could be a function of the difference between these types of discounting.

An important result of the present study concerns the magnitude effect (Thaler, 1981). The magnitude effect describes how rates of discounting vary as a function of the amount being discounted. In the case of delay discounting, rates of discounting decrease as a function of the magnitude of the outcome; presumably participants are more tolerant of delays when the outcome is of great size, severity, or importance. Conversely, in the case of probability discounting (the present procedure), rates of discounting should increase as a function of the 
magnitude of the outcome (e.g., Green et al., 1999). That is, participants presumably become more risk averse when the outcomes are of greater magnitude. In the present study, the hypothetical legal outcomes of murder and embezzlement were chosen because they were thought to differ in magnitude. Consistent with the magnitude effect, participants displayed significantly more discounting in the hypothetical murder scenario (arguably the offense with greater magnitude) than in the hypothetical embezzlement scenario.

An unexpected finding concerned differences in how people discounted hypothetically winning $\$ 100,000$ and receiving medical treatment for a serious condition. The factor analysis indicated that discounting of a probabilistic sum of money cross-loaded with discounting of medical treatment, whereas previous research using delay discounting questions indicated that they were in separate domains (Weatherly et al., 2010; Weatherly \& Terrell, 2011). Also, delay discounting studies have shown that participants discount money more than medical treatment. If this difference was a reflection of a magnitude effect, then it stands to reason that participants in the present study would have discounted medical treatment more than money (as described above, the magnitude effect for probability discounting is the inverse of that for delay discounting). However, this outcome was not observed.

Again, researchers have argued that the processes of delay and probability discounting are at least partially independent (e.g., Green \& Myerson, 2004). Perhaps the discrepant findings involving these outcomes are a reflection of the somewhat different nature of probability and delay discounting. Indeed, recent, but as yet unpublished, work from our laboratory has confirmed that participants do not discount probabilistic hypothetical medical outcomes more than probabilistic hypothetical monetary outcomes. Perhaps people tend to display self-control when the best medical outcome is certain but delayed, and risk prone when the best medical outcome is instead probabilistic. Future research that independently manipulates the size and importance of a medical outcome would bring clarity to this issue.

\section{Limitations}

The results of the present study should be viewed as preliminary; they need to be replicated and extended before strong conclusions are drawn from them. The procedure employed only university students. Likewise, the sample was made up of mostly young people, females, and Caucasians. The same results may not be observed with a more diverse sample of participants. Because race has been repeatedly shown to influence legal decisions, another limitation is that the vast 
majority of the present participants were White and the race of the defendant in the hypothetical legal scenarios was not identified.

Next, the procedure employed a certain method of collecting discounting data (i.e., the fill-in-the-blank method; Chapman, 1996) that is not the most commonly used method (see Madden \& Bickel, 2010). Research on delay discounting has found that this method sometimes produces different rates of discounting than other methods (e.g., the binary-choice method; see Smith \& Hantula, 2008). Thus similar results may not occur if a different method was used to collect the data.

Additionally, the procedure only investigated discounting in two hypothetical legal scenarios and only four hypothetical scenarios overall. It is not known if discounting of all legal scenarios would fall in the same domain, or whether discounting of some non-legal scenarios would fall completely within the same domain as legal outcomes had more outcomes been tested. Furthermore, the crime scenarios had participants discounting outcomes for someone other than themselves whereas the sweepstakes and medical treatment scenarios were phrased such that the hypothetical outcomes would occur to the participants themselves. Thus, the differences observed in the present study may be a product of who experienced the outcomes, not of legal vs. non-legal outcomes. Likewise, the differences in phrasing across the different hypothetical scenarios might have contributed to the differences in discounting that were observed. All of these possibilities are potential avenues for future research about the discounting of legal decisions.

Perhaps the main limitation of the present study, however, is that the present data represent decisions about hypothetical scenarios. Factors that predict discounting in hypothetical legal situations may not predict discounting in actual cases. There is, however, a growing body of research that suggests that discounting of hypothetical outcomes predicts or equates to the discounting of real outcomes (Bickel, Jones, Landes, Christensen, Jackson, \& Mancino, 2010; Johnson \& Bickel, 2002; Lawyer, Schoepflin, Green, \& Jenks, 2011; Locey et al., 2011). The ultimate purpose of the present research, however, is to determine how people discount plea bargains in actual cases not hypothetical situations. Thus, devising procedures that measure overt behavior, rather than ratings of hypothetical situations, would be preferable. In short, results from studies like the present one may predict overt behavior, or they may not, and conclusions should be drawn accordingly. 


\section{Conclusions}

Discounting occurs in a variety of "real world" legal situations, but the study of discounting in these situations has yet to receive systematic research attention. The results of this preliminary study indicate that rates of probability discounting of different legal outcomes may differ from each other, at least when hypothetical outcomes are tested. The results also indicate that the observed rates of discounting of the hypothetical legal outcomes differ from what would be predicted from the leading theory on plea bargaining (i.e., decision theory; McAllister \& Bregman, 1986). On the other hand, discounting in these different hypothetical legal situations appears to belong within one domain, whereas discounting of other non-legal hypothetical outcomes occurs within another domain. Knowing how individuals quantify reasonable doubt appears to predict in part how they discount plea bargains, at least as it was currently phrased. In contrast, other self-report measures on legal attitudes may not be very predictive of discounting, even in hypothetical situations. Altogether, the results from this preliminary study suggest that the study of discounting in the context of legal situations is a potentially fruitful and important endeavor.

\section{References}

Bibas, S. (2004). Plea bargaining outside the shadow of trial. Harvard Law Review,

117, 2463-2547. Retrieved from

http://go.galegroup.com/ps/i.do?id=GALE\%7CA118747144\&v=2.1\&u=undl law\&it=r\&p= $\underline{\mathrm{LT} \& \mathrm{sw}=\mathrm{W}}$

Bickel, W. K., Jones, B. A., Landes, R. D., Christensen, D. R., Jackson, L., \& Mancino, M. (2010). Hypothetical intertemporal choice and real economic behavior: Delay discounting predicts voucher redemptions during contingency-management procedures. Experimental and Clinical Psychopharmacology, 18, 546-552.

Butler, B., \& Moran, G. (2007). The impact of death qualification, belief in a just world, legal authoritarianism, and locus of control on venire persons' evaluations of aggravating and mitigating circumstances in capital trials. Behavioral Sciences \& the Law, 25, 57-68. doi:10.1002/bsl.734

Cattell, R. B. (1966). In Cattell R. B. (Ed.), Handbook of multivariate experimental psychology Rand McNally: Chicago. Retrieved from http://ezproxy.library.und.edu/login?url=http://search.ebscohost.com/login.aspx?direct=true $\& \mathrm{db}=$ psyh\&AN=1966-35009-000\&site=ehost-live \&scope $=$ site

Chapman, G. B. (1996). Temporal discounting and utility for health and money. Journal of Experimental Psychology: Learning, Memory, and Cognition, 22, 771-791. doi:10.1037/0278-7393.22.3.771

Devine, D. J., Clayton, L. D., Dunford, B. B., Seying, R., \& Pryce, J. (2001). Jury decision making: 45 years of empirical research on deliberating groups. Psychology, Public Policy, and Law, 7, 622-727. doi:10.1037/1076-8971.7.3.622 
Dhami, M. K. (2008). On measuring quantitative interpretations of reasonable doubt. Journal of Experimental Psychology: Applied, 14(4), 353-363. doi:10.1037/a0013344

Edkins, V. A. (2011). Defense attorney plea recommendations and client race: Does zealous representation apply equally to all? Law and Human Behavior, 35, 413-425. doi:10.1007/s10979-010-9254-0

Estle, S.J., Green, L., Myerson, J., \& Holt, D.D. (2006). Differential effects of amount on temporal and probability discounting of gains and losses. Memory \& Cognition, 34, 914-928.

Greene, E. \& Heilbrun, K. (2011). Wrightman's psychology and the legal system. Belmont, CA: Wadsworth.

Green, L., \& Myerson, J. (2004). A discounting framework for choice with delayed and probabilistic rewards. Psychological Bulletin, 130, 769-792. doi:10.1037/00332909.130.5.769

Green, L., Myerson, J., \& Ostaszewski, P. (1999). Amount of reward has opposite effects on the discounting of delayed and probabilistic outcomes. Journal of Experimental Psychology: Learning, Memory, and Cognition, 25, 418-427. doi:10.1037/0278-7393.25.2.418

Hardisty, D. J., \& Weber, E. U. (2009). Discounting future green: Money versus the environment. Journal of Experimental Psychology: General, 138, 329-340. doi:10.1037/a0016433

Hollander-Blumhoff, R. (1997). Getting to "guilty": Plea bargaining as negotiation. Harvard Negotiation Law Review, 2, 115-148.

Johnson, M. W., \& Bickel, W. K. (2002). Within-subject comparison of real and hypothetical money rewards in delay discounting. Journal of the Experimental Analysis of Behavior, 77, 129-146.

Kramer, G. M., Wolbransky, M., \& Heilbrun, K. (2007). Plea bargaining recommendations by criminal defense attorneys: Evidence strength, potential sentence, and defendant preference. Behavioral Sciences \& the Law, 25, 573-585. doi:10.1002/bsl.759

Lawyer, S. R., Schoepflin, F., Green, R., \& Jenks, C. (2011). Discounting of hypothetical and potentially real outcomes in nicotine-dependent and nondependent samples. Experimental and Clinical Psychopharmacology, 19, 263-274.

Lecci, L., \& Myers, B. (2008). Individual differences in attitudes relevant to juror decision making: Development and validation of the pretrial juror attitude questionnaire (PJAQ). Journal of Applied Social Psychology, 38, 2010-2038. doi:10.1111/j.15591816.2008.00378.x

Locey, M. L., Jones, B. A., \& Rachlin, H. (2011). Real and hypothetical rewards in self-control and social discounting. Judgment and Decision Making, 6, 522-564.

Madden, G. J., \& Bickel, W. K. (2010). In Madden G. J., Bickel W. K. (Eds.), Impulsivity: The behavioral and neurological science of discounting. Washington, DC: American Psychological Association. doi:10.1037/12069-000

Martin, T. A., \& Cohn, E. S. (2004). Attitudes toward the criminal legal system: Scale development and predictors. Psychology, Crime \& Law, 10, 367-391. doi:10.1080/10683160310001629265

Mazur, J. E. (1987). An adjusting procedure for studying delayed reinforcement. In M. L. Commons, J. E. Mazur, J. A. Nevin, \& H. Rachlin (Eds.), Quantitative analyses of behavior: Vol. 5. The effect of delay and of intervening events on reinforcement value. (pp. 55-73). Hillsdale, NJ England: Lawrence Erlbaum Associates, Inc. Retrieved from http://ezproxy.library.und.edu/login?url=http://search.ebscohost.com/login.aspx?direct=true $\& \mathrm{db}=$ psyh $\& A N=1986-98701-003 \&$ site $=$ ehost-live $\&$ scope $=$ site 


\section{PROBABILITY DISCOUNTING OF LEGAL AND NON-LEGAL OUTCOMES}

McAllister, H. A. (2008). Plea bargaining. In B. L. Cutler (Ed.), Encyclopedia of psychology and law: Vol. 2. (pp. 559-561), Thousand Oaks, CA: SAGE Retrieved from http://catdir.loc.gov/catdir/toc/ecip0723/2007029845.html

McAllister, H. A., \& Bregman, N. J. (1986). Plea bargaining by prosecutors and defense attorneys: A decision theory approach. Journal of Applied Psychology, 71, 686-690. doi:10.1037/00219010.71.4.686

Myerson, J., Green, L., \& Warusawitharana, M. (2001). Area under the curve as a measure of discounting. Journal of the Experimental Analysis of Behavior, 76, 235-243. doi:10.1901/jeab.2001.76-235

Odum, A. L. (2011). Delay discounting: Trait variable? Behavioural Processes, 87, 1-9. doi:10.1016/j.beproc.2011.02.007

Odum, A. L., \& Rainaud, C. P. (2003). Discounting of delayed hypothetical money, alcohol, and food. Behavioural Processes, 64, 305-313. doi:10.1016/S0376-6357(03)00145-1

Pearce, D., Groom, B., Hepburn, C., \& Koundouri, P. (2003). Valuing the future: Recent advances in social discounting. World Economics, 4, 121-141.

Petry, N. M., \& Madden, G. J. (2010). Discounting and pathological gambling. In G. J. Madden, W. K. Bickel, G. J. Madden \& W. K. Bickel (Eds.), Impulsivity: The behavioral and neurological science of discounting. (pp. 273-294). Washington, DC US: American Psychological Association. doi:10.1037/12069-010

Smith, C. L., \& Hantula, D. A. (2008). Methodological considerations in the study of delay discounting in intertemporal choice: A comparison of tasks and modes. Behavior Research Methods, 40, 940-953. doi:10.3758/BRM.40.4.940

Sweeney, L. T., \& Haney, C. (1992). The influence of race on sentencing: A meta-analytic review of experimental studies. Behavioral Sciences \& the Law, 10, 179-195. doi:10.1002/bs1.2370100204

Tabachnick, B. G., \& Fidell, L. S. (2007). Using multivariate statistics (5th ed.). Boston, MA: Allyn \& Bacon/Pearson Education. Retrieved from http://ezproxy.library.und.edu/login?url=http://search.ebscohost.com/login.aspx?direct=true $\& \mathrm{db}=$ psyh\&AN=2006-03883-000\&site=ehost-live \&scope $=$ site

Thaler, R.H. (1981). Some empirical evidence on dynamic inconsistency. Economic Letters, 8, 201-207.

Weatherly, J. N., Derenne, A., \& Terrell, H. K. (2011). Testing the reliability of delay discounting of ten commodities using the fill-in-the-blank method. The Psychological Record, 61, 113126. Retrieved from http://ezproxy.library.und.edu/login?url=http://search.ebscohost.com/login.aspx?direct=true $\& \mathrm{db}=$ psyh $\& \mathrm{AN}=2011-20531-007 \&$ site $=$ ehost-live \&scope $=$ site

Weatherly, J. N., Plumm, K. M., \& Derenne, A. (2011). Delay discounting and social policy issues. The Psychological Record, 61, 527-546. Retrieved from http://ezproxy.library.und.edu/login?url=http://search.ebscohost.com/login.aspx?direct=true $\& \mathrm{db}=$ psyh\&AN=2011-23300-002\&site=ehost-live \&scope $=$ site

Weatherly, J. N., \& Terrell, H. K. (2011). Delay discounting of different commodities II: Confirmatory analyses. Journal of General Psychology, 138, 35-48. doi:10.1080/00221309.2010.532522

Weatherly, J. N., Terrell, H. K., \& Derenne, A. (2010). Delay discounting of different commodities. Journal of General Psychology, 137, 273-286. doi:10.1080/00221309.2010.484449 
WEATHERLY, WISE, \& DERENNE

Williams, J. (2010). Attention-deficit/hyperactivity disorder and discounting: Multiple minor traits and states. In G. J. Madden, W. K. Bickel, G. J. Madden \& W. K. Bickel (Eds.), Impulsivity: The behavioral and neurological science of discounting. (pp. 323-357). Washington, DC: American Psychological Association. doi:10.1037/12069-012

Yi, R., Mitchell, S. H., \& Bickel, W. K. (2010). Delay discounting and substance abusedependence. In G. J. Madden, W. K. Bickel, G. J. Madden \& W. K. Bickel (Eds.), Impulsivity: The behavioral and neurological science of discounting. (pp. 191-211). Washington, DC US: American Psychological Association. doi:10.1037/12069-007

\section{Appendix}

The probability-discounting questions answered by the participants. $\mathrm{Y}=1$, $10,50,90$, or $99 \%$ across questions.

\section{Murder}

Defendant X committed murder and, if found guilty, will be sentenced to 100 years in prison without the possibility of parole. According to the prosecutor, if the case goes to trial, then the chances that a jury will find Defendant $\mathrm{X}$ guilty of murder is $\mathrm{Y} \%$. However, the prosecutor indicates that a plea bargain can be reached that would guarantee that Defendant $\mathrm{X}$ will serve a certain number of years in prison. How many years should the prosecutor agree to in the plea bargain rather than going to trial with a $\mathrm{Y} \%$ chance of getting a guilty verdict?

\section{Embezzlement}

Defendant X committed embezzlement and, if found guilty, will be fined $\$ 100,000$. According to the prosecutor, if the case goes to trial, then the chances that a jury will find Defendant $X$ guilty of embezzlement is $Y \%$. However, the prosecutor indicates that a plea bargain can be reached that would guarantee that Defendant $X$ will pay a certain amount of money as a fine. How much money should the prosecutor agree to in the plea bargain rather than going to trial with a Y\% chance of getting a guilty verdict?

\section{Sweepstakes}

You are a finalist in a national sweepstakes. You have a $\mathrm{Y} \%$ chance of winning $\$ 100,000$. If your number is not called, however, you do not receive anything. The organization running the sweepstakes is willing to guarantee to pay you a certain amount of money if you agree to remove your name from the 
sweepstakes. What is the smallest amount of money would you be willing to accept rather than having a Y\% chance of winning $\$ 100,000$ ?

\section{Medical Treatment}

Suppose you were suffering from a serious disease. Your physician informs you that there are two treatment options. The first one completely cures the disease, but it only works for $\mathrm{Y} \%$ of the patients who choose it. The second treatment is guaranteed to work, but it only partially treats the disease. You can only afford to choose one treatment. What is the minimum percentage of success that the second treatment would need to guarantee for you to choose it over having a Y\% chance of a full recovery? 